\title{
Blood glucose and meal patterns in time-blinded males, after aspartame, carbohydrate, and fat consumption, in relation to sweetness perception
}

\author{
Kathleen J. Melanson ${ }^{1}$, Margriet S. Westerterp-Plantenga ${ }^{1}$, L. Arthur Campfield ${ }^{2}$ and Wim H. M. Saris ${ }^{1}$ \\ ${ }^{1}$ Department of Human Biology, Maastricht University, PO Box 616, 6200 MD Maastricht, The Netherlands \\ ${ }^{2}$ Center for Human Nutrition, Department of Medicine, University of Colorado Health Sciences Center, Denver, CO 80262, USA
}

(Received 4 January 1999 - Revised 5 May 1999 - Accepted 11 June 1999)

\begin{abstract}
In a study of the impact of aspartame, fat, and carbohydrate on appetite, we monitored blood glucose continuously for 431 (SE 16) min. Ten healthy males (19-31 years) participated in three time-blinded visits. As blood glucose was monitored, appetite ratings were scored at randomized times. On the first meal initiation, volunteers consumed one of three isovolumetric drinks (aspartame, $1 \mathrm{MJ}$ simple carbohydrate, and $1 \mathrm{MJ}$ high-fat; randomized order). High-fat and highcarbohydrate foods were available ad libitum subsequently. Blood glucose patterns following the carbohydrate drink $(+1.78$ (SE 0.28$) \mathrm{mmol} / \mathrm{l}$ in 38 (SE 3) min) and high-fat drink $(+0.83$ (SE 0.28$) \mathrm{mmol} / \mathrm{l}$ in 49 (SE 6) min) were predictive of the next intermeal interval $(R 0.64$ and $R 0.97$ respectively). Aspartame ingestion was followed by blood glucose declines $(40 \%$ of subjects), increases $(20 \%)$, or stability $(40 \%)$. These patterns were related to the volunteers' perception of sweetness of the drink $(R 0.81, P=0.014)$, and were predictive of subsequent intakes $(R-0.71, P=0.048)$. For all drinks combined, declines in blood glucose and meal initiation were significantly associated $\left(\chi^{2} 16 \cdot 8, P<0 \cdot 001\right)$, the duration of blood glucose responses and intermeal intervals correlated significantly $(R 0.715, P=0.0001)$, and sweetness perception correlated negatively with hunger suppression $(R-0.471, P=0.015)$. Effects of fat, carbohydrate, and aspartame on meal initiation, meal size, and intermeal interval relate to blood glucose patterns. Varied blood glucose responses after aspartame support the controversy over its effects, and may relate to sweetness perception.
\end{abstract}

Food intake regulation: Hunger: Satiety: Aspartame

The impact of nutrient ingestion on subsequent appetite is an important yet controversial topic in the study of human food intake regulation. Carbohydrate and fat have been shown to have similar (Rolls, 1995) or different effects on satiety (Blundell et al. 1993; Hulshof et al. 1993; Lawton et al. 1993), and on intermeal interval (Himaya et al. 1997; Melanson et al. 1999), which may be related to blood glucose responses (Melanson et al. 1999). Aspartame has been shown to either increase (Blundell \& Hill, 1986; Rogers et al. 1988), decrease (Rogers et al. 1990; Rolls et al. 1990), or to not affect (Mattes, 1990; Black et al. 1991) hunger ratings and/or food intake in human subjects. The majority of studies on aspartame's effects have used simple carbohydrate as a comparison. An assumption is often made that the perception of sweetness of the drinks will be similar within and between volunteers. Sweetness has been suggested to have an impact on appetite by some (Blundell \& Hill, 1986), but not all investigators (Mattes, 1990), so it is not only important to separate the effects of sweetness and energy, but also to take sweetness perception into account.
Carbohydrate metabolism has been proposed to be instrumental in food intake regulation, due to its high turnover rate, limited storage, immediate and tight regulation, and its critical role as a fuel source for the central nervous system (Mayer, 1953; Flatt, 1996). The glucostatic hypothesis postulates that hunger signals are stimulated, at least in part, by changes in glucose utilization rates and/or blood glucose patterns in both animals (Mayer, 1953; Steffens, 1970; Louis-Sylvestre \& LeMagnen, 1980; Campfield et al. 1985) and human subjects (Campfield et al. 1996; Melanson et al. 1999). Transient declines in blood glucose have been shown to predict meal initiation in rats (Louis-Sylvestre \& LeMagnen, 1980) and fasting human subjects (Campfield et al. 1996). In the postprandial state, transient and dynamic (rapid declines following a peak induced by macronutrient ingestion) blood glucose declines have been shown to predict spontaneous meal initiation in time-blinded human subjects (Melanson et al. 1999).

In a previous study, we acutely time-blinded male volunteers, allowing them to request meals at any time as their blood glucose was continuously monitored (Melanson et al.

\footnotetext{
*Corresponding author: Dr Margriet Westerterp-Plantenga, fax +31 43367 0976, email M.Westerterp@ HB.UNIMAAS.NL
} 
Table 1. Characteristics of the subjects in the present study (Mean values, standard deviations and ranges for ten subjects)

\begin{tabular}{|c|c|c|c|}
\hline & Mean & SD & Range \\
\hline Age (years) & $25 \cdot 2$ & $4 \cdot 0$ & $19-31$ \\
\hline Weight (kg) & $77 \cdot 4$ & $11 \cdot 1$ & $51 \cdot 1-87 \cdot 5$ \\
\hline Height (m) & $1 \cdot 813$ & 0.086 & $1 \cdot 602-1.920$ \\
\hline $\mathrm{BMI}$ & 23.4 & 1.9 & $19 \cdot 9-27 \cdot 0$ \\
\hline Herman \& Polivy score* & $10 \cdot 7$ & $6 \cdot 2$ & $3-20$ \\
\hline Factor 1 score $†$ & 4.5 & $3 \cdot 1$ & $1-11$ \\
\hline Factor 2 score & 3.9 & 3.0 & $0-9$ \\
\hline Factor 3 score§ & $4 \cdot 1$ & $2 \cdot 7$ & $1-8$ \\
\hline Resting energy expenditure (kJ/min) & $5 \cdot 33$ & $0 \cdot 20$ & $4 \cdot 06-6 \cdot 78$ \\
\hline Fasting RQ & $0 \cdot 818$ & 0.012 & $0.756-0.898$ \\
\hline \multicolumn{4}{|c|}{$\begin{array}{l}{ }^{*} \text { A measure of weight-related restraint; minimum score } 0 \text {, maximum score } 35 \text {; cut-off point for } \\
\text { the Dutch population } 15 \text {. Values greater than } 15 \text { indicate restrained eating. } \\
\text { † A measure of cognitive restraint; minimum score } 0 \text {, maximum score } 23 \text {; cut-off point for the } \\
\text { Dutch population } 9 \text {. Values greater than } 9 \text { indicate cognitively restrained eating. } \\
\ddagger \text { A measure of disinhibition or emotional eating; minimum score } 0 \text {, maximum score } 20 \text {. } \\
\text { § A general feeling of hunger; minimum score } 0 \text {, maximum score } 15 \text {. }\end{array}$} \\
\hline
\end{tabular}

1999). We found that higher, more rapid blood glucose responses after simple carbohydrate compared with after high fat consumption corresponded to shorter spontaneous intermeal intervals following consumption of simple carbohydrate. In the present study, blood glucose was monitored continuously before and after ingestion of aspartame, simple carbohydrate, and high-fat preloads. Our hypothesis was that blood glucose responses would be high and rapid after simple carbohydrate, lower and prolonged after high fat, and flat after aspartame consumption, and that these patterns would be predictive of meal patterning, satiety, and energy consumption following ingestion of each preload. We also hypothesized that this relationship may be modulated by changes in energy expenditure, $\mathrm{RQ}$, and differences in sensory perception.

\section{Methods}

Subjects

Ten healthy weight-stable, non-smoking males recruited from the university community completed this protocol. They all signed informed consents, and the protocol was approved by the Medical Ethical Committee of Maastricht University. As shown in Table 1, subjects were between the ages of 19 and 31 years, and were within the normal ranges for weight, height, and BMI. Their average score on the Herman and Polivy restraint questionnaire (Herman \& Polivy, 1980), and the three-factor eating questionnaire (Stunkard \& Messick, 1985) were all within the normal range, indicating that the volunteers were not inclined to control their food intake cognitively.

Table 2. Composition of the isovolumetric test drinks containing fat, simple carbohydrate or aspartame

\begin{tabular}{|c|c|c|c|c|c|}
\hline Ingredients & $\begin{array}{l}\text { Weight } \\
\text { (g) }\end{array}$ & $\begin{array}{c}\text { Energy } \\
(\mathrm{kJ})\end{array}$ & $\begin{array}{l}\text { Fat } \\
(\mathrm{g})\end{array}$ & $\begin{array}{l}\text { Carbohydrate } \\
\text { (g) }\end{array}$ & $\begin{array}{l}\text { Protein } \\
\text { (g) }\end{array}$ \\
\hline $\begin{array}{l}\text { High-fat drink } \\
\text { Water } \\
\text { Double cream } \\
\text { Lemon syrup* }\end{array}$ & $\begin{array}{r}280 \\
62 \\
8\end{array}$ & $\begin{array}{r}0 \\
895 \\
104\end{array}$ & $\begin{array}{c}0 \\
22 \cdot 3 \\
0\end{array}$ & $\begin{array}{l}0 \\
1.9 \\
6 \cdot 2\end{array}$ & $\begin{array}{l}0 \\
1 \cdot 3 \\
0\end{array}$ \\
\hline $\begin{array}{l}\text { Totals: } \\
\text { Energy (kJ) } \\
\text { Energy (\%) }\end{array}$ & 350 & 999 & $\begin{array}{r}22 \cdot 3 \\
840 \cdot 0 \\
84.1\end{array}$ & $\begin{array}{r}8.1 \\
135.6 \\
13.6\end{array}$ & $\begin{array}{r}1.3 \\
22.5 \\
2.3\end{array}$ \\
\hline $\begin{array}{l}\text { Simple carbohydr } \\
\text { Water } \\
\text { Lemon syrup* }\end{array}$ & $\begin{array}{r}273 \\
77\end{array}$ & $\begin{array}{r}0 \\
1000\end{array}$ & $\begin{array}{l}0 \\
0\end{array}$ & $\begin{array}{c}0 \\
60 \cdot 0\end{array}$ & $\begin{array}{l}0 \\
0\end{array}$ \\
\hline $\begin{array}{l}\text { Totals: } \\
\text { Energy (kJ) } \\
\text { Energy (\%) }\end{array}$ & 350 & 1000 & $\begin{array}{l}0 \\
0 \\
0\end{array}$ & $\begin{array}{c}60 \cdot 0 \\
1000 \\
100\end{array}$ & $\begin{array}{l}0 \\
0 \\
0\end{array}$ \\
\hline $\begin{array}{l}\text { Aspartame drink } \\
\text { Water } \\
\text { Lemon juice } \\
\text { Aspartame† }\end{array}$ & $\begin{array}{r}330 \\
12 \\
8\end{array}$ & $\begin{array}{r}0 \\
16 \\
134\end{array}$ & $\begin{array}{l}0 \\
0 \\
0\end{array}$ & $\begin{array}{l}0 \\
1.0 \\
7.75\end{array}$ & $\begin{array}{l}0 \\
0 \\
0.25\end{array}$ \\
\hline $\begin{array}{l}\text { Totals: } \\
\text { Energy (kJ) } \\
\text { Energy (\%) }\end{array}$ & 350 & 150 & $\begin{array}{l}0 \\
0 \\
0\end{array}$ & $\begin{array}{c}8 \cdot 75 \\
146 \\
97 \cdot 6\end{array}$ & $\begin{array}{l}0.25 \\
4 \cdot 18 \\
2 \cdot 4\end{array}$ \\
\hline
\end{tabular}

* Karvan Cévitam ${ }^{\circledR}$ Limonadesiroop (Baarn, The Netherlands).

† Natrena ${ }^{\circledR}$ Kristalpoeder (Utrecht, The Netherlands). 


\section{Pre-protocol}

Before the protocol started, the possible test drinks and food items were evaluated. Lemon-flavoured drinks were chosen, to mask possible differences between aspartame, simple carbohydrate and high-fat drinks. The compositions of these isovolumetric test drinks are shown in Table 2. The aspartame and simple carbohydrate drinks were equally sweet; the simple carbohydrate and high-fat drinks were isoenergetic; the high-fat and aspartame drinks contained the same amount of carbohydrate. This allowed comparisons between the preloads, accounting for sweetness perception, energy, and carbohydrate content. Hedonic ratings for the drinks, after being consumed completely, were not significantly different (aspartame 65 (SE 6), carbohydrate 72 (SE 6), fat 62 (SE 10); NS). The foods offered for consumption ad libitum were typical Dutch lunch items according to food consumption surveys (Ministerie van Welzijn, Volksgezondheid en Cultuur en het ministerie van Landbouw en Visserij, 1988). They consisted of sandwiches composed of: croissants with full-fat margarine and either high-fat cheese (total sandwich (\% energy): fat 68.6 , carbohydrate $23 \cdot 2$, protein $8 \cdot 1$ ) or low-carbohydrate strawberry jam (total sandwich (\% energy): fat $64 \cdot 7$, carbohydrate $31 \cdot 1$, protein 4.0) and French bread with low-fat margarine and either low-fat cheese (total sandwich (\% energy): fat $16 \cdot 5$, carbohydrate 63.8 , protein 19.9 ) or high-carbohydrate strawberry jam (total sandwich (\% energy): fat 3.9 , carbohydrate 88.2 , protein 7.6). By selecting food items as similar as possible to each other, we took care to ensure that the tastes of the highcarbohydrate and high-fat food choices did not differ significantly, that none of the choices was preferred, and that they only differed in macronutrient composition. Hedonic ratings after consumption of the high-carbohydrate $(73 \cdot 1$ (SE 6.0)) and high-fat (74.2 (SE 4.9)) foods did not differ significantly. From these pre-protocol observations we concluded that the drinks as well as the foods were of acceptable hedonic value to the subjects, and that differences between hedonic values would not explain possible outcomes, since they did not differ significantly.

The protocol consisted of three visits, each separated by at least 1 week, to permit testing of the three different isovolumetric preload test drinks described earlier (see Table 2), in randomized order. Two of the ten volunteers came for only two visits, so there were a total of twentyeight test days in the present study. During each visit the volunteer was isolated from time cues to eliminate as much as possible habitual (time-determined) meal patterns, enabling observation of meal responses to mainly physiological cues. Therefore, volunteers reported to the laboratory at 22.00 hours on the evening before each test day, at which point the time isolation and an overnight fast began. The room where subjects stayed overnight was the same room where the testing took place the next day. No watches, clocks, radios or televisions were in this room, and research staff did not make time-related statements.

The next morning, an 18-gauge, $50 \mathrm{~mm}$ angiocath was placed in a suitable lower arm or antecubital vein of the nondominant arm. The blood withdrawal end of a speciallymodified, $2.5 \mathrm{~m}$ long double-lumen catheter (MTB Medizintechnik, Amstetten, Germany) was fitted into the angiocath. The catheter was heparinized by pumping sterile heparin-saline solution $(500-5000 \mathrm{U} / \mathrm{ml})$ at a rate of approximately $25 \mu \mathrm{l} / \mathrm{min}$ through the distal lumen of the catheter to the tip of the cannula. The blood was continuously withdrawn through the proximal lumen of the cannula at a rate of approximately $25 \mu \mathrm{l} / \mathrm{min}$. The bloodheparin-saline solution was mixed with a heparinized phosphate buffer, in the proportion $1: 10$, and continuously infused into the sample chamber of a glucose analyser (Model 23A; Yellow Springs Instrument Co., Yellow Springs, OH, USA). The resulting total blood withdrawal for the longest test day in the study (515 min) was thus less than $13 \mathrm{ml}$. The lag time of the catheter was 3-5 min, which was timed for each catheter, and accounted for in the analysis. Sampling occurred at a rate of ten times per minute, and analogue data were amplified, digitized, interfaced (Data Translation Interface Board, model 1028), and displayed continuously on a Macintosh computer monitor (Power PC, Cupertino, CA, USA) using the program Labview. This monitor was not visible to the subject. Before the insertion of the catheter into the subject, and following the completion of testing, the system was calibrated using a bag of sterile saline with added glucose to approximately $5.5 \mathrm{mmol} / \mathrm{l}$. This calibration was done using the same blood-withdrawal cannula that was used in the subject that day.

Baseline glucose concentration was determined from the continuous line over a minimum of a 30 min accommodation period. During this time, respiratory gases of the subject were analysed by ventilated-hood indirect calorimetry for the assessment of resting energy expenditure and RQ (Human Biology, Maastricht University, The Netherlands). At baseline, and at random intervals throughout the day (in order to avoid time cues), the subject completed ratings of hunger, satiety, and desire to eat on $100 \mathrm{~mm}$ visual analogue scales, anchored with such phrases as: "not at all' or 'very much'.

Throughout the test day, volunteers rested quietly, reading or studying, with minimal disturbance from the investigator. The subject was informed that he could eat and drink ad libitum from an easily-accessible cool box throughout the day. At first the cool box contained one of the three preload drinks ( $350 \mathrm{~g}$ of the aspartame, simple carbohydrate (sucrose), or high-fat beverage) (Table 2). The volunteer was asked to consume the drink in its entirety, and to complete hunger and satiety ratings before and after the preload, as well as sensory ratings of the drink during preload consumption. These sensory ratings of how pleasant, sweet, sour, salty, and bitter the volunteer perceived the drink to be, were also completed on $100 \mathrm{~mm}$ visual analogue scales. Following preload consumption, the volunteer continued studying as before the preload, aware that more food was readily available to him in the cool box.

On subsequent meal initiations, generous portions of the high-carbohydrate and high-fat food choices described earlier were present in the cool box for ad libitum consumption. The volunteer was told that he could eat as much or little as he wanted of any or all of the items offered, and that plenty more was available if he would like. The volunteer completed appetite ratings before and after each meal. Following consumption of the first ad libitum meal, bananas and 
chocolate bars were also added to the cool box for additional high-carbohydrate and high-fat options. The total energy and macronutrient contents of the foods consumed were determined by weighed differences.

Immediately after consumption of preloads and ad libitum meals, respiratory gases were again analysed as described earlier, to determine possible changes in RQ and energy expenditure. These measurements lasted 20-35 min; the duration was randomized so that the volunteer could not determine the passing of time from them. After the ventilated hood was removed from the subject, appetite ratings were completed.

The testing was pre-determined to last for a total of $6-8 \mathrm{~h}$, or until clot formation prohibited further blood glucose monitoring (in two of twenty-eight tests). On completion of the testing, volunteers were requested to estimate the clock time in order to verify that they were blinded to the time of day.

\section{Statistics}

One-minute averages of blood glucose levels over time were plotted for each volunteer's test day using the programs Microsoft Excel 4.0 and Cricket Graph 1.3 for Macintosh (Cupertino, CA, USA). The dataset was shifted forward by the exact recorded transit time of the catheter used for sampling. Based on the definition of transient blood glucose declines in the literature (Campfield et al. 1985, 1996), the blood glucose data were scanned for periods of stable baseline glucose $(\mathrm{SD} \leqslant 0.055 \mathrm{mmol} / \mathrm{l})$ lasting $5 \mathrm{~min}$ or longer, which were then followed by a decrease of at least $5(\mathrm{SD} \geqslant 2) \%$ below the stable baseline glucose level, lasting at least $5 \mathrm{~min}$. The datasets were also searched for dynamic declines in blood glucose, which have been described as rapid (0.023-0.070 mmol/l per min for 42-67 min) declines originating from a peak induced by nutrient ingestion (rather than from a stable baseline) (Melanson et al. 1999). The number of times that meal initiation occurred in the presence or absence of a transient or dynamic decline in blood glucose was quantified.
'Postabsorptive' refers to the state when all the previouslyingested food has been absorbed from the digestive tract, whereas 'postprandial' refers to the state when the digestive tract contains ingested food. Since, in the present protocol, testing started at least $10 \mathrm{~h}$ after the last nutrient ingestion, the postabsorptive state was defined as the period from the beginning of the testing until the first macronutrient consumption (preload); the postprandial state was defined from the first nutrient consumption until the end of testing.

Comparisons between the results from the different drinks were made by repeated measures ANOVA with a Scheffe $F$ test for post-hoc comparisons on the computer software program Statview 2.0 for Macintosh. Associations between changes in blood glucose and meal initiation were tested using the $\chi^{2}$ test for $2 \times 2$ contingency tables with correction for continuity (Parker, 1986). Regression analyses were utilized to test relationships between blood glucose variables, energy expenditure, RQ, sensory variables, and such outcome variables as hunger, satiety, intermeal interval, and food intake. This was performed for the three different preload drinks separately, as well as with all twenty-eight test days combined. Differences in indirect calorimetry data from before to after preload drink consumption were compared within each preload, by paired $t$ test. Statistical significance was accepted as $P \leqslant 0 \cdot 05$. Data are presented as means with their standard errors unless otherwise specified.

\section{Results}

The average duration of continuous blood glucose sampling was 431 (SD 57) min, ranging from 270 to $515 \mathrm{~min}$, and did not differ significantly among test days when the three different preload drinks were administered. The volunteers' estimation of clock time at the end of the testing ranged from -238 to $+108 \mathrm{~min}$, verifying that the subjects were time-blinded. This also did not differ between test days when the three different preload drinks were administered. Average baseline blood glucose concentrations were 4.51 (SE 0.06) $\mathrm{mmol} / \mathrm{l}$.

Table 3. Responses observed in the relationship between blood glucose patterns and meal requests in twentyeight adult male subjects

\begin{tabular}{|c|c|c|c|c|c|c|}
\hline & \multicolumn{3}{|c|}{$\begin{array}{l}\text { Declines in blood glucose } \\
\text { associated with meal requests }\end{array}$} & \multicolumn{3}{|c|}{$\begin{array}{l}\text { Meal requests associated with } \\
\text { declines in blood glucose }\end{array}$} \\
\hline & Yes & No & $\overline{\text { Total }}$ & Yes & No & Total \\
\hline Postabsorptive transient ${ }^{*}$ & $\begin{array}{l}17 \\
(94.4 \%)\end{array}$ & $\begin{array}{c}1 \\
(5 \cdot 6 \%)\end{array}$ & 18 & $\begin{array}{l}17 \\
(60 \cdot 7 \%)\end{array}$ & $\begin{array}{l}11 \\
(39 \cdot 3 \%)\end{array}$ & 28 \\
\hline Postprandial dynamic & $\begin{array}{l}22 \\
(71.0 \%)\end{array}$ & $\begin{array}{c}9 \\
(29.0 \%)\end{array}$ & 31 & 22 & & 22 \\
\hline Postprandial transient & $\begin{array}{l}15 \\
(83.3 \%)\end{array}$ & $\begin{array}{l}3 \\
(16 \cdot 7 \%)\end{array}$ & 18 & 15 & & 15 \\
\hline Postprandial collective $†$ & $\begin{array}{l}37 \\
(75.5 \%)\end{array}$ & $\begin{array}{l}12 \\
(24.5 \%)\end{array}$ & 49 & $\begin{array}{l}37 \\
(80.4 \%)\end{array}$ & $\begin{array}{c}9 \\
(19 \cdot 6 \%)\end{array}$ & 46 \\
\hline Totalł & $\begin{array}{l}54 \\
(80 \cdot 6 \%)\end{array}$ & $\begin{array}{l}13 \\
(19 \cdot 4 \%)\end{array}$ & 67 & $\begin{array}{l}54 \\
(73.0 \%)\end{array}$ & $\begin{array}{l}20 \\
(27 \cdot 0 \%)\end{array}$ & 74 \\
\hline
\end{tabular}

${ }^{*} \chi^{2} 19 \cdot 0, P<0.001$

$+\chi^{2} 20.2, P<0.001$.

$\neq \chi^{2} 16 \cdot 8, P<0.001$. 
Table 3 depicts the synchronization of meal initiations and declines in blood glucose. During the testing day, in the postabsorptive state, twenty-eight meal initiations occurred (one per day per subject); seventeen occurred in the presence of a transient decline in blood glucose, and eleven in the absence. Of the total eighteen transient blood glucose declines in the postabsorptive state, seventeen were associated with meal initiation. $\chi^{2}$ analysis revealed that in the postabsorptive state, the synchronization between spontaneous meal initiation and transient declines in blood glucose was significant $\left(\chi^{2} 19 \cdot 0, P<0.001\right)$ (Table 3$)$.

In the postprandial state, a total of forty-six meals were initiated; thirty-seven in relation to blood glucose changes: either transient declines or dynamic declines (Melanson et al. 1999). Of the forty-nine transient and dynamic declines occurring in the postprandial state, thirty-seven were associated with meal initiation. Collectively, in the postprandial state, the relationship between declines in blood glucose (transient and dynamic) and spontaneous meal initiation was statistically significant $\left(\chi^{2} 20 \cdot 2, P=0 \cdot 001\right)$ (Table 3).

Of the eighteen observed postprandial transient declines in blood glucose, fifteen were associated with spontaneous meal initiation $(83 \%)$. Thus, this interdependence was statistically significant $\left(\chi^{2} 14.8, P<0.001\right)$. The thirty-one observed dynamic declines in blood glucose constituted, on
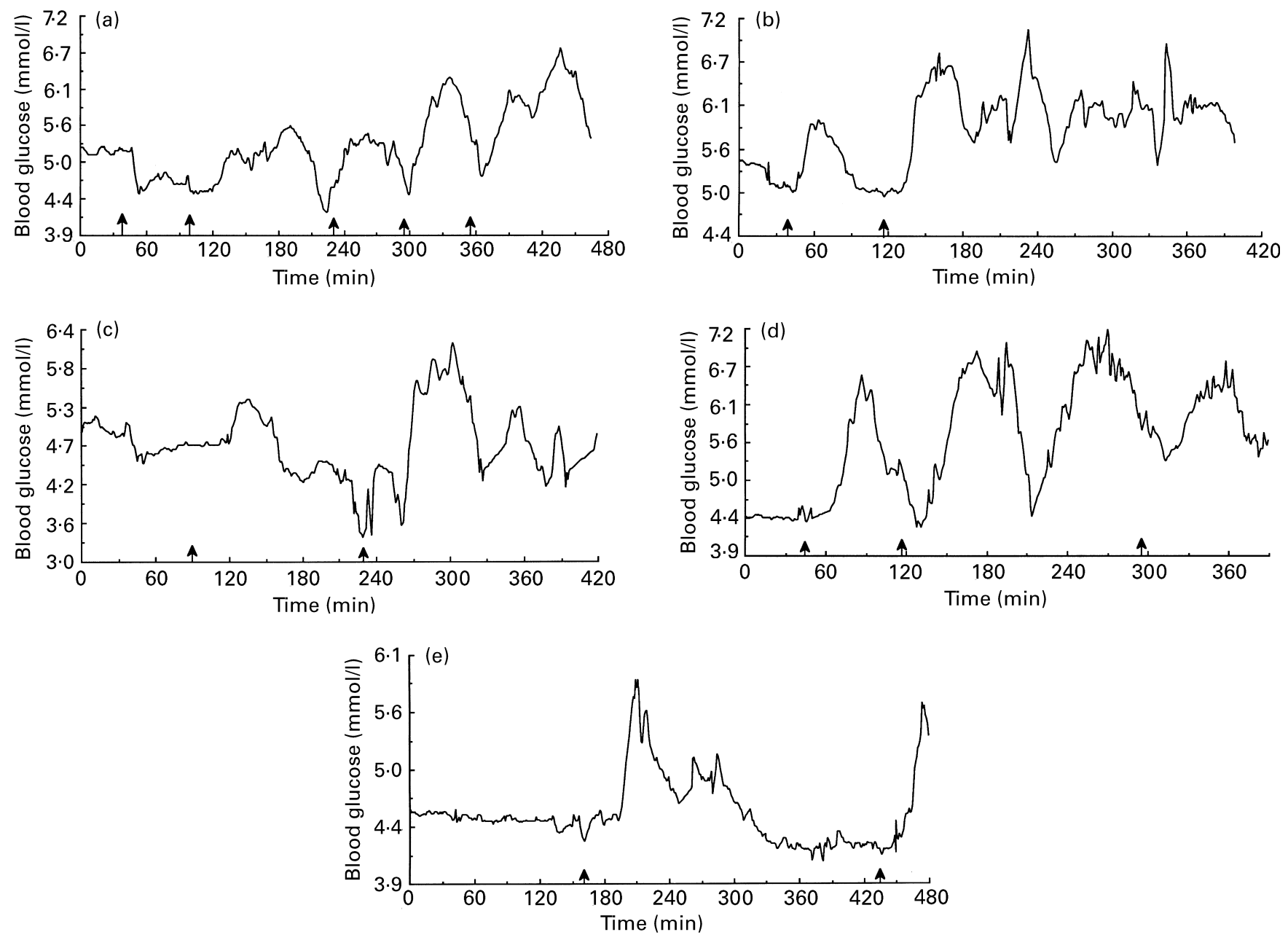

Fig. 1. (a) Blood glucose profile of an individual whose blood glucose declined by $0.61 \mathrm{mmol} / \mathrm{l}$ within 13 min of ingestion of an aspartame preload drink. The solid arrows indicate meal initiation. Meals 1 (preload) and 2 (three sandwiches) were initiated in the absence of transient declines in blood glucose, and meals 3, 4, and 5 were initiated after the nadirs of dynamic declines in blood glucose. (b) Blood glucose profile of an individual whose blood glucose increased by $0.28 \mathrm{mmol} / \mathrm{l}$ within $8 \mathrm{~min}$ of ingestion of an aspartame preload drink. The solid arrows indicate meal initiation. Meal 1 (preload) was initiated after a transient decline in blood glucose, and meal 2 (four sandwiches) was initiated at the nadir of a dynamic decline in blood glucose. (c) Blood glucose profile of an individual whose blood glucose remained stable for 34 min following ingestion of an aspartame preload drink. The solid arrows indicate meal initiation. Meal 1 (preload) was initiated in the absence of a transient decline in blood glucose, and meal 2 (three sandwiches) was initiated at the nadir of a dynamic decline in blood glucose. (d) Blood glucose profile of an individual on a test day when a simple carbohydrate preload was consumed (at minute 45). The solid arrows indicate meal initiation. Meal 1 (preload drink) was initiated in the absence of a transient decline in blood glucose, and meals 2 (three sandwiches) and 3 (one sandwich) were initiated during dynamic declines. (e) Blood glucose profile of an individual on a test day when a high-fat preload drink was consumed. The solid arrows indicate meal initiation. Meal 1 (preload drink) was initiated in the presence of a transient decline in blood glucose, and meal 2 (four sandwiches) was initiated in absence of declines in blood glucose, but after a slow return to baseline. 
average, a 28.3 (SE 2.0) \% decrease over 60.8 (SE 8.3) min, which followed a rise in blood glucose induced by meal ingestion (39.3 (SE 3.4) \% in 60.9 (SE 8.2) min). Spontaneous meal initiation occurred during twenty-two $(71 \%)$ of these declines, therefore dynamic declines in blood glucose were also significantly synchronized with meal initiation $\left(\chi^{2} 13.0, P<0 \cdot 001\right)$ (Table 3). There were no significant differences among the three different preloads in the number of postprandial declines in blood glucose, number of meal requests, or in the synchronization between meal initiation and blood glucose declines.

In Fig. 1, individual blood glucose curves over time are depicted, representing three different responses to the aspartame preload (Figs 1(a), (b), and (c)), and typical responses to the simple-carbohydrate preload (Fig. 1(d)), and to the high-fat preload (Fig. 1(e)). Following ingestion of the aspartame preload drink, three different blood glucose responses were observed: blood glucose declined by an average of 0.39 (SE 0.11$) \mathrm{mmol} / \mathrm{l}$ in 12 (SE 1$) \min (n 3$; Fig. 1(a)); blood glucose increased by an average of 0.72 (SE 0.11) mmol/l within the first 17 (SE 5) min of ingestion ( $n$ 3; Fig. 1(b)); and blood glucose remained stable for over $30 \mathrm{~min}(n$ 2; Fig. 1(c)). The increase, decrease, or stability in blood glucose after aspartame ingestion was correlated with ad libitum food intake over the rest of the day $(R-0.71, P=0.048)$, as well as with subsequent meal frequency $(R-0.784, P=0.024)$, but not with intermeal interval.

Following ingestion of the carbohydrate preload drink, blood glucose increased by an average of 1.78 (SE 0.28 ) $\mathrm{mmol} / \mathrm{l}$ in 38 (SE 3) min, then decreased by 2.22 (SE 0.33) $\mathrm{mmol} / \mathrm{l}$ (Fig. 1(d)). The next intermeal interval (80 (SE 17) min) was correlated with the length of this response $(R 0.64, P=0.045)$. Peak glucose concentrations after consumption of simple carbohydrate correlated positively with hunger at the initiation of the subsequent meal $(R 0.719, P=0.019)$. Following ingestion of the fat preload drink, blood glucose increased by an average of 0.83 (SE 0.28 ) $\mathrm{mmol} / \mathrm{l}$ in 49 (SE 6) min, then decreased by 1.33 (SE 0.28$) \mathrm{mmol} / \mathrm{l}$ (Fig. 1(e)). The next intermeal interval (112 (SE 18) min) was correlated with the length of this response $(R$ 0.97, $P=0 \cdot 0001)$. The blood glucose responses following ingestion of the simple carbohydrate compared with the high-fat preloads were significantly different for the change in blood glucose to peak $(P=0.003, F$ test 4.07) and from peak to nadir $(P=0.0004, F$ test 5.24).

For all three test drinks combined (twenty-eight tests) the duration of the blood glucose response was positively correlated with the duration of the intermeal interval $(R 0.715, P=0.0001)$ and with post-drink satiety $(R 0.519$, $P=0.007)$, as depicted in Fig. 2 . Further, post-drink satiety was positively correlated with intermeal interval for all drinks combined $(R 0.448, P=0.025)$.

As shown in Fig. 3, the change in blood glucose following ingestion of the aspartame preload drink was inversely related to the volunteers' perception of the sweetness of the drink $(R \quad 0.81, P=0.014)$. This relationship was not found for the other two test drinks. No differences in sweetness perception were rated between the carbohydrate (73.2 (SE 7.0), range 20-100) and aspartame drinks (68.3 (SE $4 \cdot 3)$, range $50-85)(F$ test $0 \cdot 32$ ), but the volunteers rated

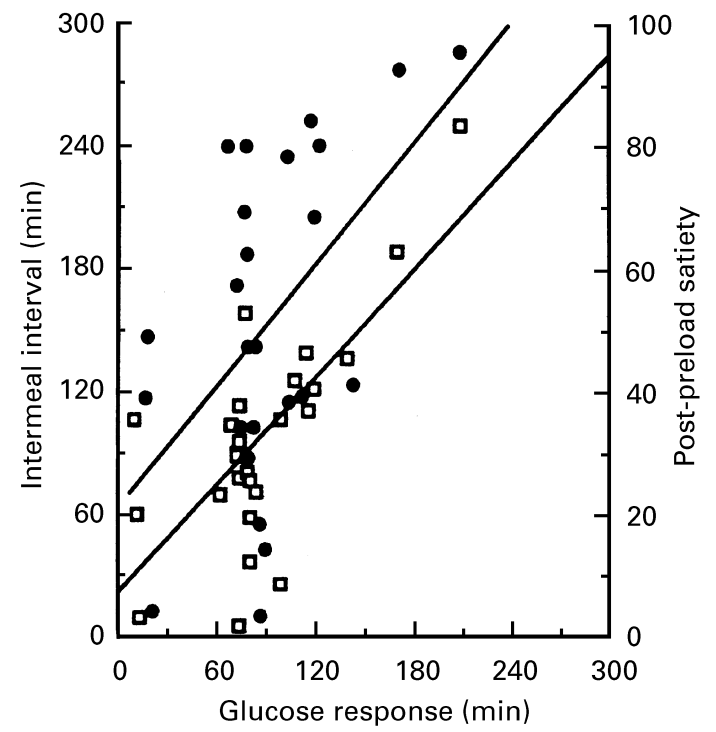

Fig. 2. Duration of the intermeal interval $(\square)$ and post-preload satiety scores $(\bullet)$ in relation to the duration of the blood glucose response to test drinks containing fat, simple carbohydrate or aspartame (all three test drinks combined; $n 10$ subjects, twenty-eight tests). ( $\square$ ), $y=$ $20.026+0.88260 x, R^{2} 0.511 ;(\bullet), y=23.879+0.32040 x, R^{2} 0.270$.

the carbohydrate drink ( $F$ test 8.357$)$ and the aspartame drink ( $F$ test 11.95) as sweeter than the fat drink (38.4 (SE 9.3), range 3-75) $(P=0 \cdot 0008)$. For all three drinks combined, sweetness perception was negatively correlated with the change in hunger from before to after drink consumption $(R-0.471, P=0.015)$. That is, the sweeter that a volunteer perceived a given drink to be, the less his hunger was suppressed by consumption of that drink. No significant differences were found between the other sensory ratings of the three different preload drinks.

Ad libitum food intakes did not differ over the remainder of the test day between days when the three different drinks were consumed (Table 4). No energy intake compensation for the group as a whole was observed after aspartame preload ingestion. The highest variability in energy and macronutrient intakes occurred following ingestion of the aspartame preload drink. The average meal frequencies after the simple carbohydrate, high-fat and aspartame preload drinks were 1.6 (SE 0.4), 1.7 (SE 0.3) and 2.8 (SE 1.0)

Table 4. Ad libitum energy and macronutrient intakes following consumption of isovolumetric preload drinks containing fat, simple carbohydrate or aspartame*

(Mean values and standard deviations)

\begin{tabular}{|c|c|c|c|c|c|c|}
\hline \multirow[t]{2}{*}{ Preload drink } & \multicolumn{2}{|c|}{$\begin{array}{c}\text { Carbohydrate } \\
\quad(n 10)\end{array}$} & \multicolumn{2}{|c|}{$\begin{array}{l}\text { Fat } \\
(n 10)\end{array}$} & \multicolumn{2}{|c|}{$\begin{array}{l}\text { Aspartame } \\
\quad(n 8)\end{array}$} \\
\hline & Mean & SD & Mean & SD & Mean & SD \\
\hline & 6112 & 910 & 61 & 66 & 5861 & 1652 \\
\hline Carbohydrate (g & 143 & 29 & 144 & 20 & 162 & 5 \\
\hline Fat $(g)$ & 84 & 13 & 72 & 12 & 70 & 20 \\
\hline Protein (g) & 32 & 4 & 30 & 3 & 32 & 7 \\
\hline
\end{tabular}

* There were no statistically significant differences. 


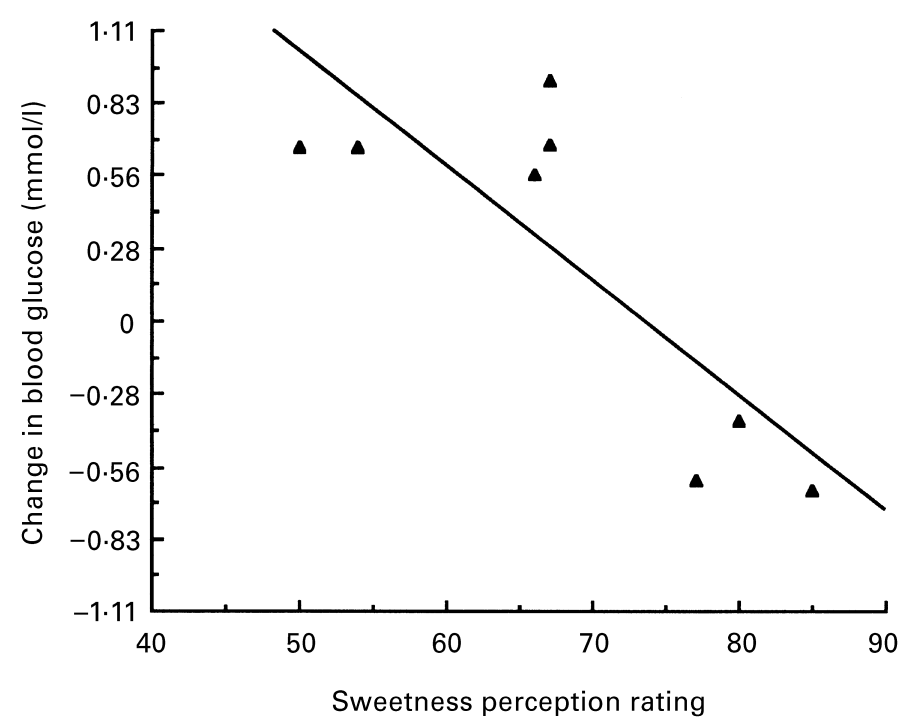

Fig. 3. Regression of change in blood glucose $(\mathrm{mmol} / \mathrm{l})$ on ingestion of an aspartame drink $v$. perception of sweetness of the drink in ten healthy male subjects. The line is described by the equation $y=57.957-0.78819 x, R^{2}$ $0.661, P=0.014$.

respectively. For the three different drinks separately or combined, no correlations were found between energy or macronutrient intakes or meal frequency and blood glucose patterns, energy expenditure, RQ, or sensory scores.

On the test day when the simple carbohydrate preload drink was consumed, RQ increased from $0 \cdot 811$ (SE 0.012) in the fasting state to 0.884 (SE 0.018) after drink consumption $(P=0.003)$. The change in RQ after consumption of the high-fat preload was not statistically significant (from 0.809 (SE $0 \cdot 01$ ) to 0.832 (SE 0.01); $P=0 \cdot 175$ ). The change in RQ was significantly higher for the carbohydrate preload than the fat preload $(P=0.016, F$ test 5.44). Although the magnitude of change in RQ after the fat and aspartame preloads was similar $(0.026 v .0 .023)$, this change did reach statistical significance for the aspartame preload (from 0.835 (SE 0.01) to 0.862 (SE 0.02); $P=0.017$ ). The increase in energy expenditure from before to after preload consumption reached significance for the simple carbohydrate and high-fat preload drinks $(0.66($ SE 0.18$) \mathrm{kJ} / \mathrm{min}, P=$ 0.005 ; and $0.58($ SE 0.21$) \mathrm{kJ} / \mathrm{min}, P=0.021$ respectively), but not for the aspartame preload drink (0.43 (SE 0.25) $\mathrm{kJ} / \mathrm{min}, P=0 \cdot 120$ ). The only significant correlate with meal patterning from the indirect calorimetry data was following the simple carbohydrate drink: the change in RQ was negatively correlated with intermeal interval $(R-0.75, P=$ 0.0126).

\section{Discussion}

In both the postabsorptive and postprandial states transient declines in blood glucose were tightly synchronized with spontaneous meal initiation in these time-blinded males. This corroborates work from other studies in which blood glucose was monitored continuously in rats (LouisSylvestre \& LeMagnen, 1980; Campfield et al. 1985) and in fasting human subjects (Campfield et al. 1996; Melanson et al. 1999). Postprandially, both transient declines (originating from a stable baseline) and dynamic declines (originating from a peak induced by macronutrient ingestion) in blood glucose were highly synchronized with spontaneous meal initiation, which we have also previously reported (Melanson et al. 1999). As suggested by Mayer (1953), this may be related to changes in rates of fuel utilization, particularly by privileged brain regions, and may be associated with the rapid rise and subsequent fall in blood glucose. The rise and fall of the glucose curve following the carbohydrate drink was steep and fast, whereas that following the fat drink was more delayed, gradual and longer. In both cases, a subsequent meal request occurred during the decline from that rise.

In the present human protocol, we manipulated blood glucose by the physiologically relevant means of aspartame or macronutrient ingestion, and observed a relationship between hunger and transient or rapid declines in blood glucose, as measured continuously in a time-blinded situation. Using a slightly different design from that of our previous study (Melanson et al. 1999), we observed synchronization with higher statistical significance, for several possible reasons. In the present study, the volunteers stayed overnight in the laboratory before testing and were tested for a longer period than in the previous study in which the volunteers reported to the laboratory in the morning. Thus, they were probably time-blinded to a greater extent, as supported by the greater range of aberrant clock time estimates at the end of the test day in the present study $(-238$ to $+108 \mathrm{~min})$ than in the previous study $(-178$ to $+24 \mathrm{~min}$ ). With a greater degree of time-blinding, volunteers may rely less on external cues, and more on physiological hunger signals to initiate food intake. Additionally, in the present study the volunteers had free access to a cool box containing food for ad libitum consumption, so the outcome variable was spontaneous meal initiation rather than meal requests. This may be a less intimidating approach than if the volunteers had to vocalize their food 
request. Furthermore, the inclusion of snack items (chocolate and bananas) in addition to the sandwiches provided greater selection. Both increased food availability and variety in this study seemed to promote more food intake compared with the previous study (Melanson et al. 1999), and this food intake occurred in association with transient and dynamic declines in blood glucose.

The inter-individual variability observed in blood glucose responses following ingestion of the aspartame preload was related to subsequent spontaneous intermeal intervals, meal frequency and ad libitum food intakes. Ingestion of aspartame has been reported to either increase (Blundell \& Hill, 1986; Rogers et al. 1988; Tordorf \& Alleva, 1990), decrease (Rolls et al. 1988, 1990; Rogers et al. 1990), or not change (Black et al. 1991) short-term hunger and/or food intake in human subjects. Similarly, studies lasting $2-7 \mathrm{~d}$ have shown aspartame to be related to increased (Lavin et al. 1997), decreased (Van Itallie et al. 1988), or unchanged (Foltin et al. 1988; Mattes, 1990) food intake. All three of these responses were observed in the present study. High intersubject variability is frequently reported in studies regarding aspartame's effects (Bruce et al. 1987; Teff et al. 1991, 1995; Abdallah et al. 1997).

Variability in blood glucose responses to aspartame may be caused by inter-individual variability in the magnitude or timing of insulin responses, neuronal responses and/or gastric emptying. It has been suggested that responses to aspartame may be related to the sweetness of the drink (Blundell \& Hill, 1986; Rogers et al. 1990). Enhanced appetite was reported when volunteers tasted aspartame $v$. when they consumed aspartame as capsules (Rogers et al. 1990). In the present study, volunteers differed in their perception of the sweetness of the aspartame drink, and their related differences in blood glucose response were predictive of their food intake over the remainder of the day. These differences in metabolic responses may be related to individual subject characteristics, their sensory perceptions, the vehicle used, or a combination of these. The vehicle used in the present study was a lemonade which combined sweet and sour flavours, thus resulting in a wide range of perceptions of sweetness which correlated negatively with blood glucose change. It has also been suggested that differing degrees of exposure to the sweet taste could result if subjects gulped the drink $v$. if they sipped the drink (Rogers et al. 1990), and that the sufficiency of the stimulus may have an impact on an individual volunteer's responses (Bruce et al. 1987).

In the present study, for all drinks combined, higher perceptions of sweetness of the drinks were associated with less hunger suppression following their consumption. Sweet taste has been suggested to stimulate appetite by some (Blundell \& Hill, 1986; Rogers et al. 1988; Tordoff \& Alleva, 1990) but not all investigators (Mattes, 1990; Rodin et al. 1990; Rolls, 1991). The sweet taste of aspartame, in combination with the sight and smell of food has been shown to result in decreased blood glucose and increased insulin concentrations (Bruce et al. 1987). In that study, the volunteers' blood glucose response correlated negatively with their combined subjective sensory scores, which is similar to our result of the negative correlation between blood glucose response and sweetness perception. Hedonic ratings and/or palatability have been shown to relate to insulin responses in the cephalic phase of ingestion in some studies (Lucas et al. 1987), but not all (Teff et al. 1991, 1995).

High variability in cephalic-phase responses has been reported by some investigators (Sjöström et al. 1980; Bruce et al. 1987; Lucas et al. 1987; Teff et al. 1991, 1995). Since plasma insulin was not measured in the present study, we cannot make assumptions about how it may have responded to aspartame ingestion. Some studies have reported cephalic-phase decreases in blood glucose in certain individuals without corresponding increases in plasma insulin (Bruce et al. 1987; Abdallah et al. 1997). It has been suggested that in these cases, decreased cephalic-phase blood glucose levels may be due to direct neuronal suppression of hepatic glucose output (Bruce et al. 1987). It is possible that the volunteers in the present study had varying degrees of the combined effects of insulin and neuronal control of blood glucose levels during the cephalic phase.

Aspartame is a dipeptide (L-aspartyl-L-phenylalanine methyl ester) which is hydrolysed intestinally to aspartic acid, phenylalanine and methanol, which are then absorbed. L-Phenylalanine has been reported to stimulate the release of cholecystokinin, a potent anorectic hormone (Meyer \& Grossman, 1972; Gibbs \& Smith, 1986). Some investigators have suggested that consumption of aspartame may result in post-ingestive appetite-suppressive effects which may interact in a complex manner with the appetite-stimulatory effects of aspartame's sweet taste (Blundell \& Hill, 1986; Rogers et al. 1990). If this is the case, it may help to explain some of the inter-individual variability in responses to aspartame in the present study, as well as others, particularly in ad libitum food intake (Bruce et al. 1987; Teff et al. 1991, 1995; Abdallah et al. 1997).

Previous studies with carbohydrate and fat preloads ranging from 420 to $1850 \mathrm{~kJ}$, and intermeal intervals ranging from 30 to $315 \mathrm{~min}$ have shown no difference between the preloads in regulating subsequent ad libitum food intake (Driver, 1988; Foltin et al. 1990; Rolls et al. 1991; de Graaf et al. 1992; Warwick et al. 1993). However, some studies have found carbohydrate more satiating than fat (van Amelsvoort et al. 1990; Blundell et al. 1993; Lawton et al. 1993), whereas others have reported a stronger satiating effect of fat (Hulshof et al. 1993). In those studies, the amount of food consumed was the outcome variable, and in our present study, the outcome variable was the interval until the next spontaneous meal initiation. Across this subject-determined interval, significant increases in hunger and desire to eat, and decreases in satiety were observed. The observed responses to the carbohydrate and fat preloads, in terms of blood glucose dynamics, food intake, and intermeal interval have been reported previously from our laboratory (Melanson et al. 1999). We have confirmed these findings, and demonstrated strong correlations with blood glucose responses. Rapid blood glucose responses were associated with short intermeal intervals whereas longer blood glucose responses were associated with longer intermeal intervals in these time-blinded, freely-feeding males.

The positive correlations between duration of blood glucose responses, satiety, and intermeal interval support the hypothesis that blood glucose patterns are involved in the physiological regulation of meal patterns, although they 
cannot prove causality. It has previously been reported that postprandial elevations in blood glucose and other indices of carbohydrate metabolism are related to suppressed hunger and enhanced satiety (Raben et al. 1996). In that study, a positive correlation was found between postprandial satiety and carbohydrate oxidation, which has also been reported by other investigators (Langhans, 1996; Westerterp-Plantenga et al. 1999). In contrast, in the present study, following the simple carbohydrate drink, higher RQ were associated with shorter intermeal intervals. An important distinction is that this drink contained $100 \%$ simple carbohydrate, compared with the complex carbohydrate used in the previously-mentioned study (Raben et al. 1996). Furthermore, RQ was measured during the first $20-30 \mathrm{~min}$ after consumption, when blood glucose was peaking. Subsequently, blood glucose declined rapidly and was associated with initiation of the next meal. Change in satiety immediately after drink consumption correlated with rapidity of blood glucose increase, yet higher peak glucose concentrations were associated with higher hunger ratings at the next meal initiation. These combined findings suggest that volunteers who rapidly absorbed the carbohydrate from the drink into the bloodstream felt satiated more quickly, but the higher that blood glucose peaked, the more hungry they were before the subsequent meal. Thus, higher RQ and blood glucose values immediately after consumption of simple carbohydrate may relate to greater hunger later. In the present study, RQ was measured during a window of time with high carbohydrate availability after simple carbohydrate consumption. This relationship may differ for complex carbohydrates and mixed meals (it was not observed for aspartame or high-fat preloads), especially if indirect calorimetry is performed for a longer period of time to capture the full postprandial course of carbohydrate availability.

In conclusion, spontaneous meal initiation in timeblinded males was synchronized postabsorptively with transient declines in blood glucose, and postprandially with transient and dynamic declines in blood glucose. Changes in blood glucose following consumption of aspartame, simple carbohydrate and high-fat preloads collectively (and individually for the carbohydrate and fat preloads) were predictive of the next spontaneous intermeal interval. After ingestion of the aspartame preload, inter-individual variability in spontaneous intermeal interval and in ad libitum food intakes were related to differences in blood glucose responses. High sweetness perception was related to less hunger suppression after all drinks combined, and to lower blood glucose after the aspartame preload. This variability in responses supports the controversy regarding aspartame's effects.

\section{Acknowledgements}

Joan Senden and Loek Wouters are gratefully acknowledged for their assistance, expertise and technical advice. This study was supported by Maastricht-Wageningen MENU-VLAG.

\section{References}

Abdallah L, Chabert M \& Louis-Sylvestre J (1997) Cephalic phase responses to sweet taste. American Journal of Clinical Nutrition 65, 737-743.
Black RM, Tanaka P, Leiter LA \& Anderson GH (1991) Soft drinks with aspartame: effect on subjective hunger, food selection, and food intake of young adult males. Physiology and Behavior 49, 803-810.

Blundell JE, Burley VJ, Cotton JR \& Lawton CL (1993) Dietary fat and the control of energy intake: evaluating the effects of fat on meal size and postmeal satiety. American Journal of Clinical Nutrition 57, 722S-728S.

Blundell JE \& Hill AJ (1986) Paradoxical effects of an intense sweetener (aspartame) on appetite. Lancet i, 1092-1093.

Bruce DG, Storlein LH, Furler SM \& Chisholm DJ (1987) Cephalic phase metabolic responses in normal weight adults. Metabolism 36, 721-725.

Campfield LA, Brandon P \& Smith FJ (1985) On-line continuous measurement of blood glucose and meal pattern in free-feeding rats: the role of glucose in meal initiation. Brain Research Bulletin 14, 605-616.

Campfield LA, Smith FJ, Rosenbaum M \& Hirsch J (1996) Human eating: evidence for a physiological basis using a modified paradigm. Neuroscience and Biobehavioral Reviews 20, 133-137.

de Graaf C, Hulshof T, Weststrate JA \& Jas P (1992) Short-term effects of different amounts of protein, fats, and carbohydrates on satiety. American Journal of Clinical Nutrition 55, 33-38.

Driver CJI (1988) The effect of meal composition on the degree of satiation following a test meal and possible mechanisms involved. British Journal of Nutrition 60, 441-449.

Flatt JP (1996) Carbohydrate balance and body weight regulation. Proceedings of the Nutrition Society 55, 449-465.

Foltin RW, Fischman MW, Emurian CS \& Rachlinski JJ (1988) Compensation for caloric dilution in humans given unrestricted access to food in a residential laboratory. Appetite 10, 13-24.

Foltin RW, Fischman MW, Moran TH, Rolls BJ \& Kelly TH (1990) Caloric compensation for lunches varying in fat and carbohydrate content by humans in a residential laboratory. American Journal of Clinical Nutrition 52, 969-980.

Gibbs J \& Smith GP (1986) The roles of peptides from the stomach and the intestine. Federation Proceedings 45, 1391-1395.

Herman CP \& Polivy J (1980) Restrained eating. In Obesity, pp. 208-224 [A Stunkard, editor]. Philadelphia, PA: WB Saunders.

Himaya A, Fantino M, Antoine J-M, Brondel L \& Louis-Sylvestre J (1997) Satiety power of dietary fat: a new appraisal. American Journal of Clinical Nutrition 65, 1410-1418.

Hulshof T, de Graaf C \& Weststrate JA (1993) The effects of preloads varying in physical state and fat content on satiety and energy intake. Appetite 21, 272-286.

Langhans W (1996) Role of the liver in the metabolic control of eating: what we know - and what we do not know. Neuroscience and Biobehavioral Reviews 20, 145-153.

Lavin JH, French SJ \& Read NW (1997) The effect of sucrose- and aspartame-sweetened drinks on energy intake, hunger and food choice of female, moderately-restrained eaters. International Journal of Obesity 21, 37-42.

Lawton CL, Burley VJ, Wales JK \& Blundell JE (1993) Dietary fat and appetite control in obese subjects: weak effects on satiation and satiety. International Journal of Obesity 17, 409-416.

Louis-Sylvestre J \& LeMagnen J (1980) A fall in blood glucose level precedes meal onset in free-feeding rats. Neuroscience and Biobehavioral Reviews 4, 13-15.

Lucas F, Bellisle F \& Di Maio A (1987) Spontaneous insulin fluctuations and the preabsorptive insulin response to food ingestion in humans. Physiology and Behavior 40, 631-636.

Mattes R (1990) Effects of aspartame and sucrose on hunger and energy intake in humans. Physiology and Behavior 47, 10371044.

Mayer J (1953) Glucostatic mechanisms in the regulation of food intake. New England Journal of Medicine 249, 13-16.

Melanson KJ, Westerterp MS, Smith FJ, Campfield LA \& Saris 
WHM (1999) Blood glucose patterns and appetite in timeblinded humans: carbohydrate versus fat. American Journal of Physiology 46, R337-R345.

Meyer JH \& Grossman MI (1972) Comparison of D- and Lphenylalanine as pancreatic stimulants. American Journal of Physiology 222, 1058-1063.

Ministerie van Welzijn, Volksgezondheid en Cultuur en het ministerie van Landbouw en Visserij (1988) Wat eet Nederland: Resultaten van de voedselconsumptiepeiling 1987-1988 (What the Dutch Eat: Results from the Food Consumption Survey 19871988). The Hague, The Netherlands: Ministerie van Welzijn.

Parker RE (1986) Introductory Statistics for Biology, 2nd ed. London: Edward Arnold.

Raben A, Holst JJ, Christiansen NJ \& Astrup A (1996) Determinants of postprandial appetite sensations: macronutrient intake and glucose metabolism. International Journal of Obesity 20 , $161-169$.

Rodin J (1990) Comparative effects of fructose, aspartame, glucose, and water preloads on calorie and macronutrient intake. American Journal of Clinical Nutrition 51, 428-435.

Rogers PJ, Carlyle J, Hill AJ \& Blundell JE (1988) Uncoupling sweet taste and calories: comparison of the effects of glucose and three intense sweeteners on hunger and food intake. Physiology and Behavior 43, 547-552.

Rogers PJ, Pleming HC \& Blundell JE (1990) Aspartame ingested without tasting inhibits hunger and food intake. Physiology and Behavior 47, 1239-1243.

Rolls BJ (1991) Effects of intense sweeteners on hunger, food intake, and body weight: a review. American Journal of Clinical Nutrition 53, 872-881.

Rolls BJ (1995) Carbohydrates, fat and satiety. American Journal of Clinical Nutrition 62, 1086S-1095S.

Rolls BJ, Hetherington M \& Laster LJ (1988) Comparison of the effects of aspartame and sucrose on food intake. Appetite 11, Suppl. 1, 62-67.

Rolls BJ, Kim S \& Fedoroff IC (1990) Effects of drinks sweetened with sucrose or aspartame on hunger, thirst, and food intake in men. Physiology and Behavior 48, 19-26.
Rolls BJ, Kim S, McNelis AL, Fischman MW, Foltin RW \& Moran TH (1991) Time course of effects of preloads high in fat or carbohydrate on food intake and hunger ratings in humans. American Journal of Physiology 260, R756-R763.

Sjöström L, Garellick G, Krotkiewski M \& Luyckx A (1980) Peripheral insulin in response to the sight and smell of food. Metabolism 29, 901-909.

Steffens AB (1970) Plasma insulin content in relation to blood glucose level and meal pattern in the normal and hypothalamic hyperphagic rat. Physiology and Behavior 5, 147-151.

Stunkard AJ \& Messick S (1985) The three-factor eating questionnaire to measure dietary restraint and hunger. Journal of Psychosomatic Research 29, 71-83.

Teff KL, Devine J \& Engelman K (1995) Sweet taste: effect on cephalic phase insulin release in men. Physiology and Behavior 57, 1089-1095.

Teff KL, Mattes RD \& Engelman K (1991) Cephalic phase insulin release in normal weight males: verification and reliability. American Journal of Physiology 216, E430-E436.

Tordoff MG \& Alleva AM (1990) Oral stimulation with aspartame increases hunger. Physiology and Behavior 47, 555-559.

van Amelsvoort JMM, van Stratum P, Kraal JH, Lussenburg RN \& Houtsmuller UMT (1990) Effects of meal size reduction on postprandial variables in male volunteers. Annals of Nutrition and Metabolism 34, 163-174.

Van Itallie TB, Yang M-U \& Porikos KP (1988) Use of aspartame to test the "Body weight set point" hypothesis. Appetite 11, Suppl. 1, 68-72.

Warwick ZS, Hall WG, Pappas TN \& Schiffman SS (1993) Taste and smell sensations enhance the satiating effect of both a highcarbohydrate and a high-fat meal in humans. Physiology and Behavior 53, 553-563.

Westerterp-Plantenga MS, Rolland V, Wilson SAJ \& Westerterp KR (1999) Satiety related to 24-hour diet-induced thermogenesis during high protein/high carbohydrate versus high fat diets, measured in a respiration chamber. European Journal of Clinical Nutrition 53, 495-502. 